\title{
МИНЕРАЛЬНЫЕ ВКЛЮЧЕНИЯ Os-Ir-Ru COCТАВА И СУЛЬФИДОВ ЭПГ В Pt-Fe ИНТЕРМЕТАЛЛИДАХ ИЗ РОССЫПЕЙ, СВЯЗАННЫХ С КЛИНОПИРОКСЕНИТ- ДУНИТОВЫМИ МАССИВАМИ СРЕДНЕГО УРАЛА
}

\author{
Паламарчук Р.С., Степанов С.Ю., Козлов А.В. \\ Санкт-Петербургский горный университет, palamarchuk22@yandex.ru
}

\section{Введение}

Уральский платиноносный пояс представляет собой цепочку клинопироксенит-дунитовых массивов, протянувшуюся вдоль Уральского хребта, с которыми связана серия россыпных систем. Несмотря на уникальность некоторых россыпных объектов, таких как Исовско-Туринская или Нижнетагильская россыпные системы, минералы платиновой группы (МПГ) из них изучены не достаточно полно. Для некоторых россыпных систем (Нясьминская, Вересовоборская, Исовско-Туринская и др.) последние крупные исследования были проведены Н.К. Высоцким в начале прошлого века [1].

Общей особенностью ассоциаций платиноидов из россыпей, связанных с клино-пироксенитдунитовыми массивами является абсолютное преобладание Pt-Fe твердых растворов: самородной платины, изоферроплатины $\left(\mathrm{Pt}_{3} \mathrm{Fe}\right)$, железистой платины $\left(\mathrm{Pt}_{2} \mathrm{Fe}\right)$, а также минералов изоморфного ряда тетраферроплатина $(\mathrm{PtFe})$ - туламинит $\left(\mathrm{Pt}_{2} \mathrm{FeCu}\right)$ - никельферроплатина $\left(\mathrm{Pt}_{2} \mathrm{FeNi}\right)$. Они слагают индивиды и агрегаты, которые иногда содержат минеральные включения, представленные преимущественно минералами Os-Ir-Ru состава, а также сульфидами ЭПГ изоморфных рядов лаурит-эрликманит $\left(\mathrm{RuS}_{2}-\mathrm{OsS}_{2}\right)$ и кашинит-бауит $\left(\mathrm{Ir}_{2} \mathrm{~S}_{3}-\mathrm{Rh}_{2} \mathrm{~S}_{3}\right)$. Цель данной работы - описание морфологических особенностей и характеристика состава таких минеральных включений.

\section{Образцы и методы исследования}

За 2015-2016 гг. были опробованы россыпи, связанные с клинопироксенит-дунитовыми массивами Среднего Урала: Нижнетагильским, Светлоборским, Вересовоборским и Каменушенским. Материал был взят из 10 точек опробования. Пробы были промыты на лотке. Из полученного шлиха платиноиды были извлечены «методом» отдувки. Морфологические особенности были исследованы с помощью методов растровой электронной микроскопии с использованием микроскопов: CamScan MX2500 (ФГБУ «ВСЕГЕИ», аналитик А.В. Антонов) и CamScan MV2300 (Институт экспериментальной минералогии РАН, аналитик Д.А. Варламов). Химический состав определен с помощью рентгеноспектральногомикроанализатораCamebax SX50сволновымидетекторами(МГУим.М.В.Ломоносова, г. Москва, аналитик Д.А. Ханин).

\section{Минералы Os-Ir-Ru состава}

Среди включений данного состава явно преобладает иридистый осмий. Почти всегда он образует отдельные, идиоморфные кристаллы пинакоидального габитуса размером до 0.2 мм (рис. 1, a). Пластинки иридистого осмия часто сохраняют свой идиоморфизмный облик, находясь на поверхности Pt-Fe агрегатов, что связано с более высокой устойчивостью осмия к механическому истиранию по сравнению с окружающими его минералами (Pt-Fe, хромшпинелиды, оливин и др.).

Включения кристаллов иридистого осмия и хромшпинелидов в изоферроплатине могут соприкасаться собственными гранями (рис. 1,6 ) или кристаллы иридистого осмия проявляют больший идиоморфизм по отношению к хромпинели, образуя включения непосредственно в хромшпинелиде (рис. 1, г). Встречаются зональные зерна хромшпинелидов, внешние, обогащенные железом зоны которых обрастают пластинки иридистого осмия (рис. 1, в). На границах между иридистым осмием и хромшпинелидом отмечаются тонкие прожилки осмистого иридия.

Состав иридистого осмия колеблется в широких пределах: от 51 до 96,6 ат. \% Os, от 0 до 38 ат. \% Ir и от 0 до 19 ат. \% Ru. Содержание Rh может достигать 5 ат. \%, при среднем количестве 0.9 ат. \%. Содержание Pt, Pd обычно ниже пределов обнаружения. В большинстве своем кристаллы иридистого осмия однородны и не обладают ярко выраженной зональностью. Однако в россыпях, связанных с Каменушенским массивом, найдены зональные индивиды иридистого осмия (рис. 1, д), в которых зональность выражена сменой иридийсодержащего осмия с примесями Ru до 7 ат. \% и Rh до 1 ат. \% на минералы со значительным количеством Ru (до 21 ат. \%) и большим содержанием Rh (до 3 ат. \%). 

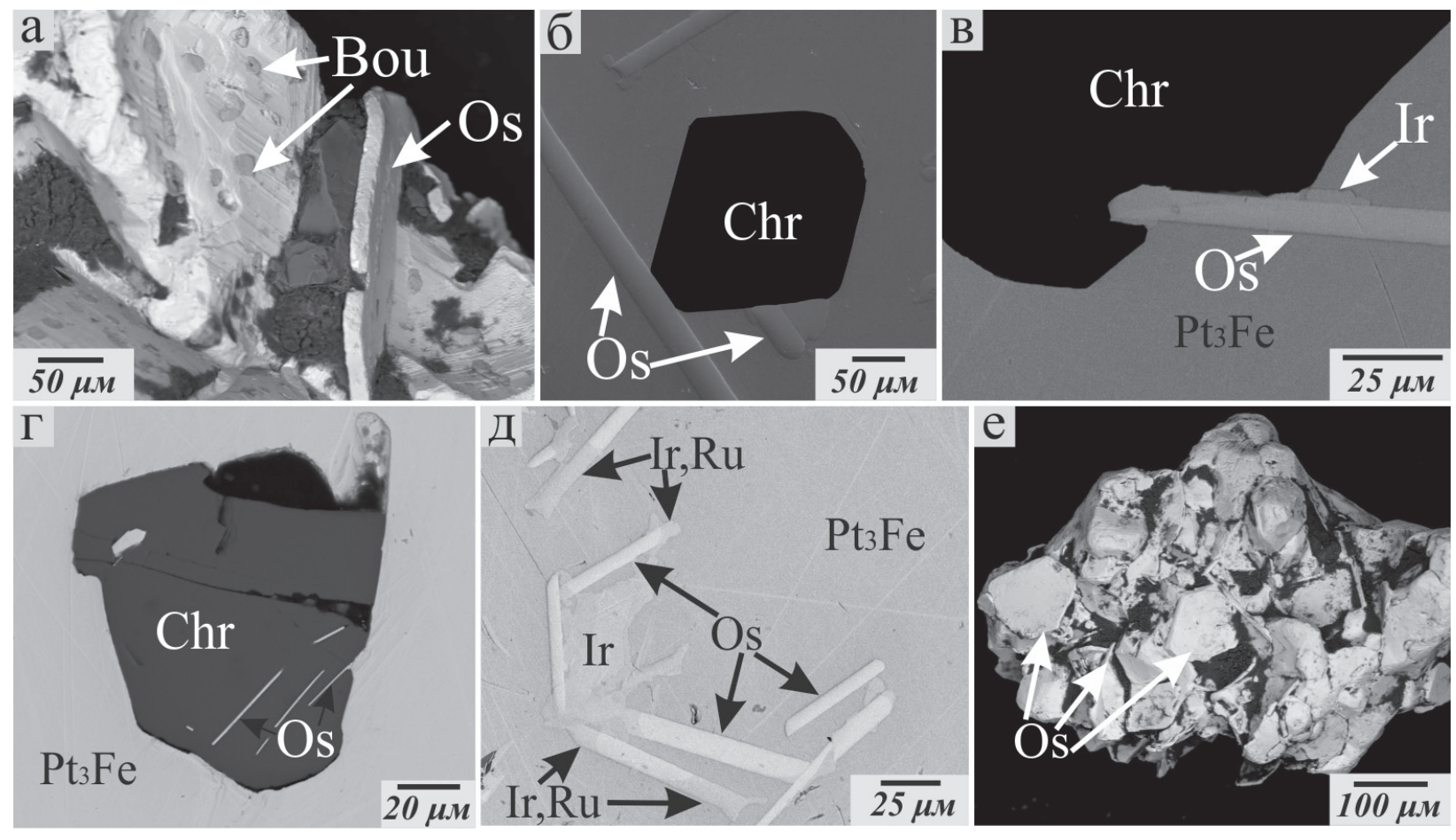

Рис. 1. Включения иридистого осмия (Os) в Pt-Fe агрегатах из россыпей Каменушенского (a-в, д-е) и Вересовоборского (г) массивов. Pt3Fe - изоферроплатина, $\mathrm{Chr}$ - хромшпинелид, $\mathrm{Ir}$ - иридий, $\mathrm{Ir}, \mathrm{Ru}$ - близ рутениридосмин, Bou - бауит. СЭМ-фотографии в режиме BSE.

Распространенность иридистого осмия в различных россыпных системах резко отличается (рис. 2). В россыпях Каменушенского массива он может составлять до $50 \%$ от Pt-Fe агрегата (см. рис. 1, е), тогда как в Нижнетагильских россыпях иридистый осмий встречается редко. Россыпная система Светлоборского массива характеризуется его более широким распространением, но ощутимо меньшим, чем в исследованных Каменушенских россыпях. Распространеность иридистого осмия может отличаться и в россыпях, связанных с одним коренным источником. Так, платиноиды из россыпи р. Простакишенка, располагающейся на западном склоне Вересовоборского массива, характеризуются единичными включениями иридистого осмия, а в Pt-Fe минералах из россыпи p. Вересовка, расположенной на севере массива, его включения многочисленны.

Среди минеральных включений также встречается осмистый иридий. Он образует как минимум 4 морфологические разновидности. Наиболее широко встречается осмистый иридий как результат распада Pt-Fe-Ir твердого раствора. Он может образовывать пластинчатую или эмульсион-
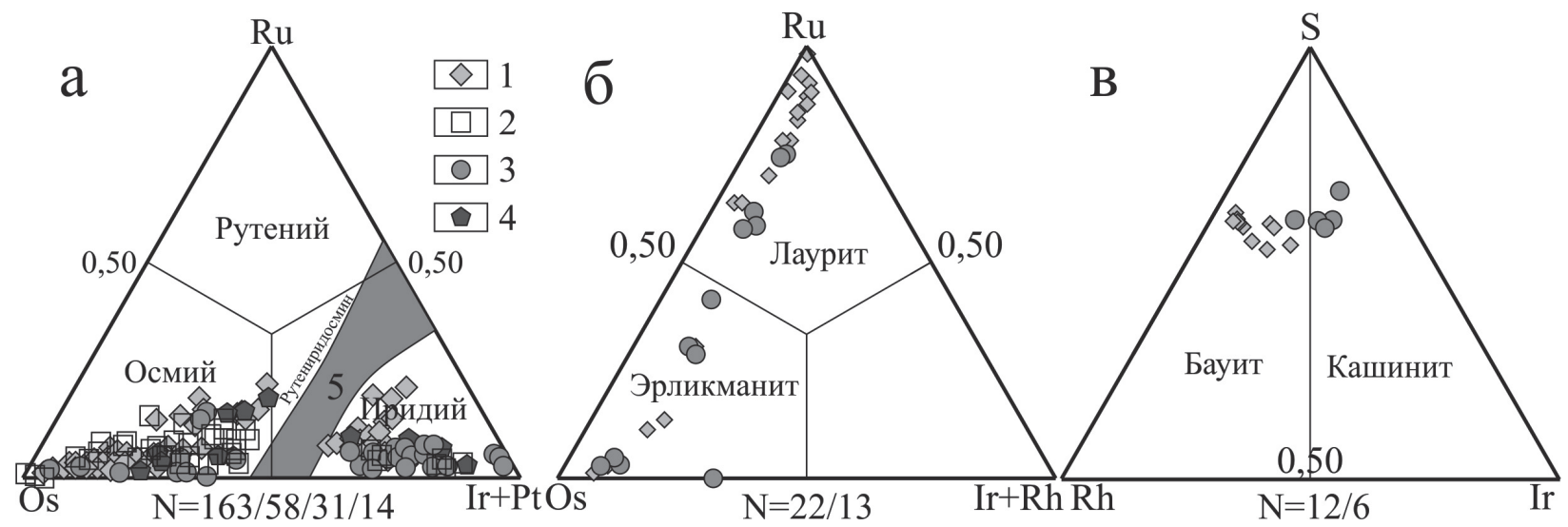

Рис. 2. Составы и относительная распространенность минералов Os-Ir-Ru состава (а) и сульфидов ЭПГ (б, в). $\mathrm{N}$ - количество анализов минеральных включений в Pt-Fe интерметаллидах из россыпей связанных с Каменушенским (1)/Вересовоборским (2)/Светлоборским (3)/Нижнетагильским (4) клинопироксенит-дунитовыми массивами. 5 - область несмесимости. Для б, в: $\mathrm{N}$ - сульфиды ЭПГ россыпей Каменушенского/Светлоборского массивов. 

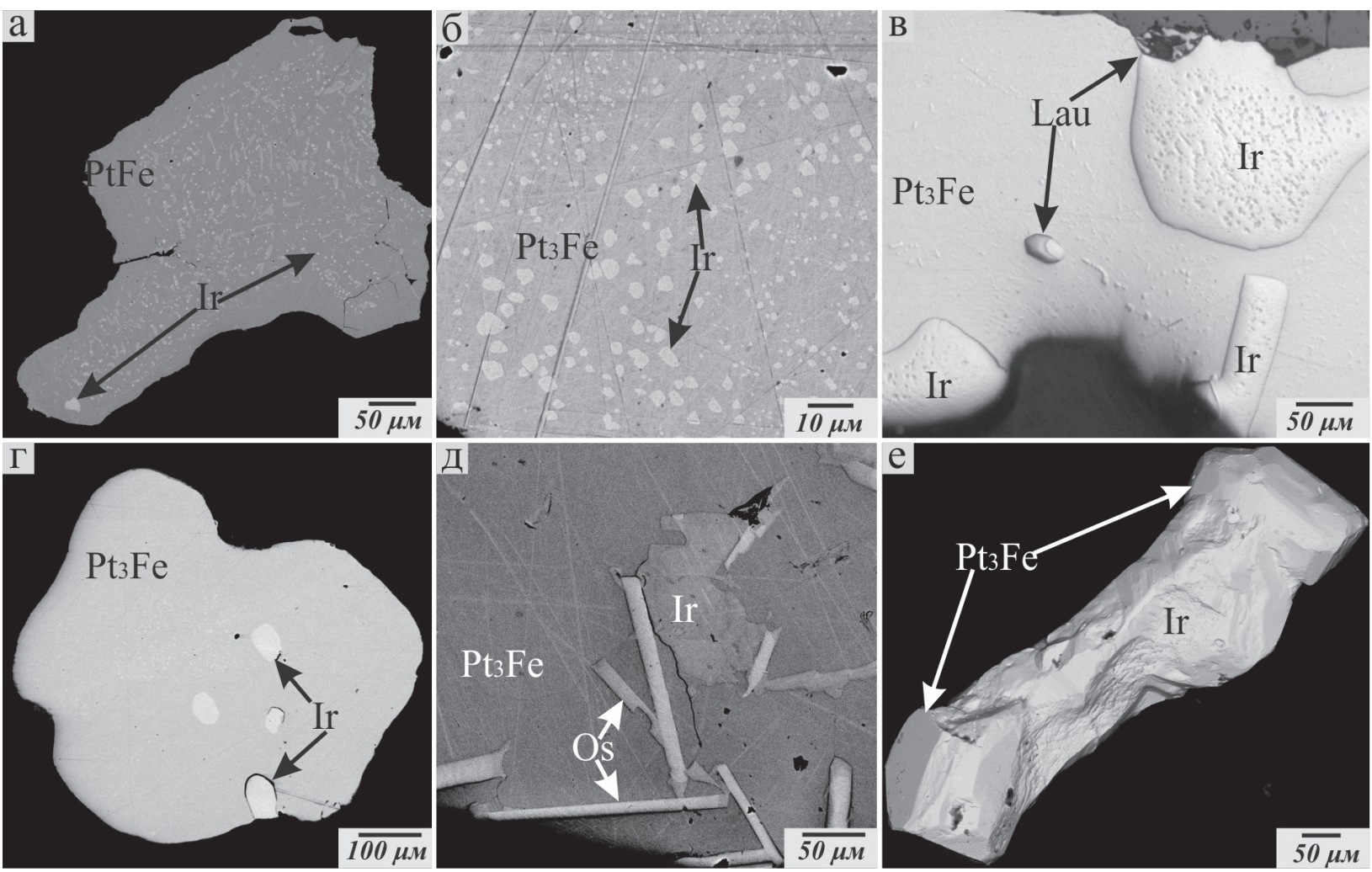

Рис. 3. Включения осмистого иридия в Pt-Fe минералах из россыпей, связанных с Нижнетагильским (a), Светлоборским $(б, г$, е) и Каменушенским (в, д) клинопироксенит-дунитовыми массивами. СЭМ-фотографии в режиме BSE.

ную вкрапленность (рис. 3, а, б). Осмистый иридий также встречается в виде самостоятельных обособлений с плавными границами (1-й морфологический тип, рис. 3, в, г). Размеры таких обособлений могут достигать 150 мкм. В некоторых образованиях осмистого иридия присутствует мелкая вкрапленность изоферроплатины (см. рис. 4, a), также результат распада твердого Pt-Fe-Ir pacтвора. В пространственной ассоциации с зональными кристаллами иридистого осмия, описанными выше, расположены обособления с резкими, извилистыми границами, представляющие 2-й морфологический тип осмистого иридия (см. рис. 1, д, 3 , д). В единичном количестве, и только в россыпях, связанных со Светлоборским массивом были найдены крупные зерна осмистого иридия с массой до 12 г. Такие индивиды характеризуются срастанием с изоферроплатиной (рис. 3 , е), при развитии индукционных и ксеноморфных поверхностей.

Состав осмистого иридия, также как и у иридистого осмия, колеблется в широких пределах (рис. 2, a). Количество Ru может достигать 21 ат. \%. Основными примесными компонентами является Pt и Rh (до 8 ат. \%). При анализе средних составов осмистого иридия двух морфологических типов отмечается полное соответствие по содержанию Os и $\mathrm{Ru}$, и отличие по Ir и Rh. Согласно этим значениям, первый тип иридия является более Ir-Pt, второй - более Rh.

Как и иридистый осмий, осмистый иридий встречается в исследуемых россыпных системах в различном количестве. Так, для россыпей, связанных с Нижнетагильским и Вересовоборским масси-
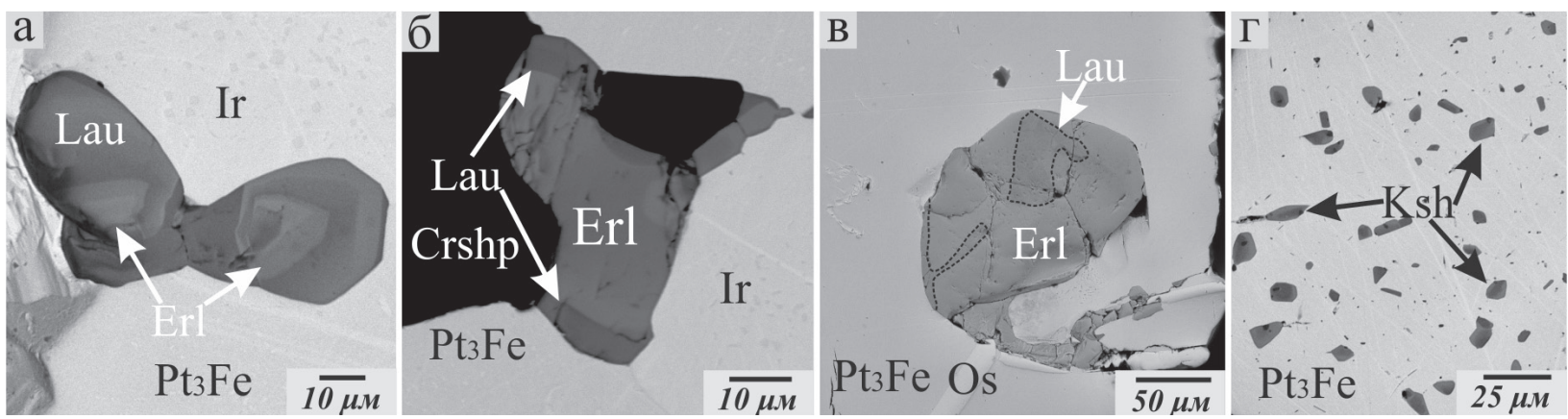

Рис. 4. Сульфиды ЭПГ в Pt-Fe минералах из россыпи Каменушенского массива. 
вами отмечается только его эмульсионные выделения. В россыпях Каменушенского массива осмистый иридий встречается во всех возможных разновидностях в значительном количестве. Светлоборские россыпи отличаются находками крупных самородков осмистого иридия весом до 12 г.

При таком значительном отличие по распространенности, в целом, для иридий- осмиевых минералов из всех россыпных систем отмечается одинаково широкий диапазон колебаний их состава (см. рис. 2, а).

\section{Сульфиды ЭПГ}

Сульфиды ЭПГ представлены минералами изоморфных рядов лаурит-эрликманит и кашинитбауит. Они встречаются значительно реже, чем включения Os-Ir-Ru состава.

В качестве включений в Pt-Fe минералах наиболее часто встречается лаурит, образуя индивиды со сложным огранением и преобладанием прямолинейных граней (рис. 4, a) с размерами до 70 мкм. Он идиоморфен относительно иридия и изоферроплатины, при этом частично срастается с хромшпинелидом (рис. 4, б). Большинство индивидов лаурита зональны, что в общем случае выражается в увеличении эрликманитового минала от периферии к центру зерна.

Эрликманит встречается реже. Он образует крупные (до 110 мкм) индивиды с изометричным обликом с прямолинейными границами (рис. 4, в) и сложными кристаллографическими формами, либо может обладать более прямолинейными границами, по форме напоминающим гексагональную пластинку осмия.

Как и другие минеральные включения, лаурит и эрликманит характеризуются широкой вариацией составов вплоть до образования крайних членов изоморфного ряда (см. рис. 2, б, в).

Кашинит и бауит встречается в заметно подчиненном количестве. Они образуют мелкие зональные зерна распределенные равномерно по единичным Pt-Fe агрегатам (рис. 4, г).

Включения сульфидов ЭПГ распределены по россыпным системам еще более неравномерно, чем минералы Os-Ir-Ru состава. Так, в россыпях Нижнетагильского и Вересовоборского (за исключением россыпи р. Вересовка) массивов они встречаются в единичных зернах. Хотя в россыпях, связанных со Светлоборским и Каменушенским массивами, сульфиды ЭПГ встречаются в заметном количестве (рис. 3, б, в).

\section{Заключение}

Таким образом, исследованные россыпные системы различаются не только по особенностям ассоциаций Pt-Fe минералов [4], но и по ассоциациям минеральных включений в них. При сравнительном анализе полученных нами анализов с литературными данными по коренному хромитплатиновому оруденению клинопироксенит-дунитовых массивов Среднего Урала [2; 3; 5] в общем случае установлена идентичность ассоциаций минеральных включений в россыпи и коренном источнике. Присутствие сульфидов ЭПГ во всех россыпных системах и резкое различие по распространенности говорит об одинаковом диапазоне фугитивности серы для всех массивов Среднего Урала, при первоначально разном ее количестве.

Авторы благодарны А.В. Антонову, Д.А. Ханину и Д.А. Варламову за проведенные аналитические работы.

Работа выполнена при поддержке гранта РФФИ № 18-35-00151\18.

\section{Литература}

1. Высоцкий Н.К. Платина и районы её добычи. Тр. КЕПС. Петроград. 1923. №№ 2-3. 343 с.

2. Пушкарёв Е.В., Аникина Е.В., Гарути Дж., Заккарини Ф. Хром-платиновое оруденение нижнетагильского типа на Урале: Структурно-вещественная характеристика и проблема генезиса. Литосфера. 2007 № 3. 28-65 C.

3. Степанов С.Ю., Малич К.Н., Козлов А.В., Баданина И.Ю., Антонов А.В. Платиноидная минерализация Светлоборского и Вересовоборского клинопироксенит-дунитовых массивов Среднего Урала (Россия). Геология рудных месторождений. Москва: Наука. 2017. № 3. Т. 59. С. 238-250.

4. Palamarchuk R.S. Stepanov S.Yu. Characteristics of platinum placers associated with Uralian-Alaskian complex in Middle Urals // Abstract volume XI L.L. Perchuk International School of Earth Sciences. Miass, 2017. P. 35-37.

5. Tolstykh N.D., Telegin Yu.M., Kozlov A.P. Platinum mineralization of the Svetloborsky and Kamenushinsky massifs (Urals Platinum Belt). Russian Geology and Geophysics. 2011. V. 52, P. 603-619. 